GEOUSP - Espaço e Tempo, São Paulo, No 28, pp. 59 - 72, 2010

\title{
A CIDADE CONTRA A CIDADE: TRAJETÓRIAS CURITIBANAS EM CONFLITO ${ }^{1}$
}

\author{
Rosirene Martins Lima*
}

\section{RESUMO}

A agenda urbana atual prioriza a inserção das cidades no mercado global. As políticas urbanas orientadas segundo critérios de competitividade e "sustentabilidade" valorizam determinados espaços em detrimento de outros, obrigando a população que não pode pagar por essa cidade a se deslocar para áreas periféricas, "fora" da centralidade do modelo. Em Curitiba esse processo acirrou as contradições na ocupação da cidade. O planejamento urbano foi eficaz, de modo a manter afastada de Curitiba a "pobreza", induzindo uma ocupação "seletiva" e "segregadora". Objetiva-se refletir sobre as estratégias de uma comunidade de catadores de material reciclável, denominada ocupação irregular, para viver na cidade. Essas áreas "estigmatizadas" explicitam as contradições das políticas urbanas, que produzem "a modernização da miséria".

Palavras-chave: Políticas urbanas, Curitiba, Catadores de Material Reciclável, Conflitos, Contradições

\section{ABSTRACT}

The current urban agenda prioritizes the inclusion of cities in the global market. Urban policies targeted on the criteria of competitiveness and sustainability, value certain spaces over others, forcing residents who can not pay for this city to move to outskirts areas, "outside" the center of the model. In Curitiba the process sharpened the contradictions in the occupation of the city. Urban planning was effective, in order to keep "poverty" away from Curitiba, inducing a "selective" and "segregated" occupation. This work aims to reflect on the strategies of a community of recyclable material, called the occupation illegal to live in the city. These "stigmatized" areas explain the contradictions of urban policy, producing "modernization of poverty."

Keywords: Urban policies, Curitiba, Recyclable Material Collectors, Conflicts, Contradictions

\section{Introdução}

Atualmente a agenda urbana tem colocado como prioridade a inserção das cidades no mercado global. As cidades vêm sendo pensadas e projetadas sob a perspectiva de atender as demandas desse mercado. A cidade entendida como uma máquina de produzir riquezas leva os gestores urbanos a uma disputa por investimentos e adequação desta aos apelos do mercado. Esse processo tem gerado contradições e fragmentação do tecido urbano. As políticas urbanas orientadas segundo critérios de competitividade e de sustentabilidade, ao valorizarem determinados espaços urbanos em detrimento de outros, obriga parte da população que não pode pagar pelos benefícios a se deslocar para áreas periféricas, aqui compreendidas como "fora" da centralidade do modelo.

$\mathrm{Na}$ cidade de Curitiba-PR, esse processo tem acirrado as contradições na ocupação dos espaços urbanos. O planejamento recorta a cidade, valorizando e desvalorizando determinados espaços conforme os interesses em jogo no momento. O planejamento pôde organizar, em Curitiba, o impacto do crescimento populacional e o respectivo uso do solo, uma vez

*Geógrafa, Mestrado em Geografia - UFPR -Doutora em Meio Ambiente e Desenvolvimento- UFPR - Professora dos Cursos de Pós-Graduação em Desenvolvimento Socioespacial e Regional - UEMA - São Luis- MA- Brasil 
que detinha a norma e o mercado imobiliário ao seu favor, induzindo o crescimento da ocupação para áreas periféricas internas e principalmente para além dos seus limites administrativos (MOURA, 2001). O planejamento urbano, no dizer da autora, foi extremamente eficaz na aplicação das políticas urbanas, de modo a manter afastada de Curitiba a "pobreza". Ele funcionou como uma espécie de barreira, inibindo ou mesmo impedindo as pessoas de usufruírem dos benefícios conquistados. Hierarquizou os espaços urbanos, funcionando como indutor de uma ocupação "seletiva" e "segregadora".

Este trabalho tem como objetivo refletir sobre as contradições identificadas no processo de ocupação e expansão da cidade de Curitiba a partir das estratégias utilizadas por uma comunidade de catadores de material reciclável para construir e se manter no lugar onde vive. Analisa alguns elementos que constituem importantes referências na construção das condições de sobrevivência dessa comunidade de catadores de material reciclável, como um fragmento urbano e, cuja especificidade lhe confere o caráter de lugar. Um lugar dentre tantos outros da cidade de Curitiba, mas que se encontra no limiar entre pertencer à cidade e ser negado por ela, na medida em que contradiz as imagens produzidas sobre Curitiba. Não pertencer à cidade, decorre de um processo sistemático de negação, que é reforçado diariamente por tudo o que o constitui, incluindo as pessoas, o tipo de trabalho que esse essa comunidade realiza e o material que manipulam. Contudo, é importante lembrar que essas áreas urbanas "estigmatizadas" tornaram-se comuns nas cidades brasileiras, pois explicitam as enormes contradições existentes, decorrentes do crescimento econômico que tem privilegiado a concentração da renda. Assim, as cidades se caracterizam pelas extremas desigualdades sócioespaciais, cuja configuração se apresenta como ilhas de prosperidade e de "marginalidade", colocadas de forma antagônicas.

A reflexão aqui proposta toma como ponto de partida um fragmento urbano determinado, que pode ser "enquadrado" naquilo que Wacquant (2001) denominou de espaços da "marginalidade". Os espaços da "marginalidade", em oposição aos espaços da prosperidade servem para explicar as situações vivenciadas pelos moradores do Jardim Icaraí. Para eles, há "duas cidades": uma que vêem e outra em que vivem, sendo que esta cidade na qual vivem "não existe oficialmente", uma vez que não é reconhecida e nem consta no mapa da cidade de Curitiba. A dualidade da cidade, conforme apontado por Santos (2004) sobre os dois circuitos é mostrado como ela aparece no cotidiano da população, "fora" dos circuitos, das ilhas de prosperidade. O esforço dos moradores, portanto, para tornar o Jardim Icaraí, parte da cidade traduz-se no processo de construção das condições de sua existência e nas estratégias de resistência para continuar no lugar, pois é no cotidiano que a razão de viver é buscada em face de uma racionalidade hegemônica (SANTOS, 2000).

Nesse sentido, a reflexão proposta se debruça sobre o olhar desses moradores, que manifestam suas verdades, por meio da maneira como pensam e constroem a cidade a partir de suas práticas sociais cotidianas. Práticas essas que se encontram inscritas para além do Jardim Icaraí, especializadas também nos caminhos percorridos pelas ruas e avenidas da cidade, quando da coleta do material reciclável, pois é no cotidiano que se constroem outras racionalidades e temporalidades, encontradas para além do credo da ortodoxia econômica, que só vê um sentido, o do lucro (SANTOS, 2000). Mesmo na cidade é possível identificar e encontrar situações diversas das professadas ela ortodoxia econômica, que rivalizam com um modo de viver da cidade, como mercadoria (LEFEBVRE,1991). Tal modus operandi possibilita a esses sujeitos se posicionarem, dizendo o que pensam e como vêem a cidade de Curitiba.

\section{A comunidade do Jardim Icarai}

Do viaduto sobre a ferrovia, à direita, quem vem do município de São José dos Pinhais em direção à Curitiba, depara-se com uma paisagem de lagoas cobertas por vegetação de macrofitas aquáticas, margeadas por um aglomerado de habitações "precárias". Este cenário difere daquele apregoado pelo discurso 
sobre Curitiba como cidade que serve de modelo para outras cidades do Brasil. Essa imensa área foi utilizada de forma "predatória" por empresas mineradoras de areia e saibro, que retiravam legal ou ilegalmente grandes quantidades desses recursos destinados à construção civil de Curitiba. Foi esse tipo de ação predatória ao meio ambiente que se estendeu de forma sistemática por um período de vários anos (aproximadamente desde a década de 1950). Esse processo transformou aquela parte da várzea do rio Iguaçu, em uma área "inóspita" e, contraditoriamente, imprópria para a própria expansão da cidade.

O capital que gerava o processo de expansão da cidade era o mesmo que impunha obstáculos ao seu crescimento, pois ao alterar profundamente a área, comprometia o seu uso e impedia quaisquer outras formas que não fossem as já realizadas. Os interesses em jogo naquele momento restringiam-se a essa atividade de exploração mineral. A atividade de exploração de areia, que por si já é predatória, acentua-se nessa área de grande fragilidade ambiental, gerando impactos no meio ambiente devido à remoção dos solos, modificando o relevo, a qualidade da água e provocando profundas alterações na paisagem. As cavas, enquanto "passivos ambientais" resultantes das lavras de exploração da areia, se prara uns se apresentam como problemas, para outros constituem possibilidades, ou seja, elemento "facilitador" de um processo que se desencadeia com a ocupação da área. As dificuldades colocadas, inicialmente, e que se apresentaram de forma visível devido à degradação da área, afastaram momentaneamente os interesses de exploração comercial que poderiam se tornar um elemento inibidor ou mesmo proibidor da ação de ocupação, atribuída de ilegal. O elemento "facilitador" ao qual se fez referência é o fato de ser uma área desprovida de valor comercial por conta das condições de degradação, pois as jazidas de areia que serviam como atrativo comercial, já haviam atingido a exaustão e, por isso mesmo, estavam completamente abandonadas. Quando cessaram as lavras de areia, sobraram as cavas como "passivos ambientais", muitas delas transformadas em lagoas, devido às chuvas e às cheias do rio Iguaçu.

Independentemente da origem ou da fonte da alteração da paisagem que levou à degradação da área, o mais importante para as pessoas que ali chegaram era organizar as condições "mínimas" a fim de construir suas casas. Isso implicava, num primeiro momento, conseguir identificar os locais mais firmes e seguros do terreno, longe das lagoas e das possíveis enchentes que pudessem vir a ocorrer. Os primeiros ocupantes construíram suas habitações na parte mais alta, mais seca, próximo à linha do trem. No entanto, pelo fato de a área ser de várzea, tal procedimento não implicava garantia de não ser atingido por eventuais inundações, pois toda vez que chovia, a maior parte da área sofria com a cheia, provocando uma série de transtornos às pessoas, que muitas vezes ficavam impossibilitadas de transitar pela área e, conseqüentemente, de sair para trabalhar. Segundo os moradores, um dos motivos que os levou a ocupar a área se relaciona à localização, que para eles, fica próxima ao centro da cidade de Curitiba, ou seja, próximo aos locais de coleta de material reciclável.

Á medida que foram sendo ocupadas as áreas mais altas pelas "novas famílias" que chegavam ao local, restavam apenas as estreitas faixas de terra que dividiam as lagoas, e que também foram utilizadas para a construção de novas moradias que se perfilavam nas suas bordas. A ausência de "terra firme" não impediu que novas famílias continuassem chegando ao local, o que levou a um novo processo de aterramento, muito mais complexo e dispendioso para as famílias, pois se tratava do aterramento das lagoas e das cavas, que necessitavam de uma maior quantidade de entulhos até que tivessem condição para a construção das casas. As famílias aterraram as cavas e lagoas com restos de material de construção, que era adquirido dos caçambeiros por um preço considerado alto pelas famílias, já que não tinham alternativa para construir suas casas a não ser expandindo o solo através do aterro.

Aquilo que as construtoras jogavam fora, o que não servia mais como matéria para a 
edificação das casas dos bairros considerados mais nobres da cidade, foi matéria-prima essencial para a construção das moradias das famílias do Jardim Icaraí. As residências em sua maioria são construídas de materiais reaproveitados, e a madeira é o tipo de material predominante. Uma pesquisa amostral realizada pela COHAB em 2006, na Vila Audi/União, da qual o Jardim Icaraí é parte, também indicou a predominância da madeira nas construções dos domicílios, aproximando-se de $77,1 \%$, e 14,81 de alvenaria e o restante de materiais reaproveitados. É importante ressaltar que a madeira utilizada pelos moradores é resultante de demolições de antigas casas de madeira de outros bairros de Curitiba.

Fato interessante a ressaltar é a contradição do processo, pois grande parte dos entulhos utilizados para aterrar as cavas e lagoas, foi anteriormente areia retirada desse mesmo local ou de locais como esses, ou seja, das várzeas do rio Iguaçu, e que agora num processo inverso, serve para restituir e "recompor", de certa maneira, a várzea do rio. Trata-se de uma expansão da cidade sobre área degradada, tanto do ponto de vista natural, quanto do pondo de vista social. Do ponto de vista natural, a degradação é resultante de um processo de exploração predatória da natureza, especificamente, da areia retirada para a construção civil. Do ponto de vista social, a degradação estaria relacionada às condições sociais em que se encontram as famílias desprovidas de toda sorte de recursos capaz de garantir a própria sobrevivência. Essa falta de condição as coloca fora dos parâmetros de uso da cidade, ou seja, não possuem as mínimas condições para poder pagar e assim usufruir dos bens de consumo que a cidade oferece, principalmente, a moradia, por se tratar de bem de difícil acesso para as famílias de baixa renda. Desta forma, tudo aquilo que é considerado desprovido de utilidade torna-se sobra, descartável, e por isso é separado do que tem lugar e utilidade nos limites dessa cidade. Na falta de lugar na cidade, essas famílias buscam construir seu próprio espaço "fora" daqueles limites impostos e demarcados pelo mercado, que impõe preços que eles não podem pagar.
Esse fragmento da cidade "descartável", já que desprovido dos atributos compatíveis com a cidade que é projetada, é que vai servir para abrigar os "indesejáveis": os entulhos da construção civil e os seres humanos que não podem pagar para viver na cidade planejada, na cidade legal. O fato de poder equiparar os Homens aos entulhos, na medida em que são obrigados a estar no mesmo local, dá a dimensão do modelo de cidade que se constrói. Paradoxalmente a essa lógica, esses Homens constroem uma cidade dentro da cidade que se materializa sob outra lógica, outra ordem e outra legalidade, localizada para além dos dispositivos jurídicos, que determinam as formas de uso e de apropriação da cidade de Curitiba, ou como diz Santos (1999) constroem uma contrarracionalidade.

Do ponto de vista social, econômico e geográfico, essas contrarracionalidades, se localizam entre os pobres, os excluídos, as "minorias", entre as atividades marginais e nas zonas "opacas" (SANTOS, 1999). É por isso que as famílias que ocuparam a área encontram-se completamente "livres" para produzir aquele espaço de acordo com suas próprias regras e com as suas necessidades mais vitais, incluindo o aterramento das cavas e das lagoas para a construção de suas casas. Contudo, esse processo de aterramento das cavas e das lagoas não se faz sem conflitos, já que o Jardim Icaraí encontra-se inserido numa área de preservação ambiental (Cf. Decreto No 192, de 29 de março de 2000) e, portanto, sujeita a uma regulamentação própria e à observância de preceitos que regem as unidades de conservação (Cf. Lei 9.985, de 18 de julho de 2000). Ademais, a Lei de Zoneamento Urbano (Cf. Lei N 9.800/2000) destinou essa área para a preservação ambiental ao mesmo tempo em que condicionou o seu uso a algumas situações previamente determinadas. Portanto, há uma incidência de diversos dispositivos legais que afetam diferentemente á Área de Proteção do Iguaçu com o objetivo de disciplinar e controlar o seu uso. A quantidade e a variedade de dispositivos legais que se apresentam e que servem para disciplinar o uso da área não representa um elemento inibidor do processo, uma 
vez que as famílias desconhecem tal legislação, e também porque possuem uma compreensão a respeito da preservação do meio ambiente, que difere da compreensão do poder público.

Dessa forma, o Jardim Icaraí foi erguido pelos próprios moradores sobre os escombros da exploração mineral da área no vale do rio Iguaçu. A sua particularidade reside nesse fato e num outro que pode ser percebido quando se caminha pelo Jardim, e se observa que quase tudo ali construído é produto do lixo produzido em Curitiba. Tudo ali é (re)aproveitado e (re)inventado, assemelhando-se a uma grande colcha de retalhos, onde cada fragmento, cada pedacinho de material "sem valor", passa a ter utilidade e compor o todo. Nesse lugar, importa salientar, tudo ou quase tudo foi construído pelas famílias, na ausência do Poder Público Municipal. Desde o aterramento das cavas e das lagoas, a abertura e aterramento das ruas e toda uma "infraestrutura mínima", como a abertura e aterramento das ruas, instalação da água e da energia elétrica por meio artesanal e clandestino.

A maioria dos moradores do Jardim Icaraí são "carrinheiros" ou "carroceiros", ou como se autodenominam, trabalhadores com material reciclável. O fato dessa atividade não ser formalmente regulamentada, é como se não existisse apesar de exerceram a atividade regularmente. No caso específico de Curitiba, vale ressaltar que, a despeito da série de slogans para divulgar o projeto em que se encontra envolta a gestão municipal de caráter de justiça social, os programas referentes à coleta do lixo (tais como: "Lixo que não é Lixo", "Cambio Verde" e "Compra do Lixo"), não contemplam o envolvimento dos carrinheiros ou carroceiros como participantes efetivos. Foi nesse processo de total "subversão às regras", à Lei e a uma determinada ordem, que foram construindo o lugar, cujo sentido deve ser compreendido no contexto da trajetória vivenciada pelas famílias que se encontram morando no Jardim Icaraí. As reflexões a seguir orientam-se no sentido de tomar alguns aspectos da atividade de coleta do material reciclável para aí estabelecer uma relação desses agentes e sua atividade no contexto da construção do lugar, do Jardim Icaraí, uma vez que a maioria das famílias trabalha nessa atividade de coleta. Busca se explicitar a seguir a as trajetórias e os conflitos envolvendo os carrinheiros e carroceiros durante a atividade da coleta do material reciclável.

\section{Trajetórias e Conflitos}

As trajetórias percorridas no interior da cidade para a realização da atividade da coleta do material reciclável são bastante longas e penosas, conforme depoimento dos próprios carrinheiros e carroceiros. Alem de percorrem entre 8 a 12 km, ou mais, não dispõe das condições adequadas para a realização do seu trabalho; sofrem constrangimentos, pois incomodam o trafego e porque disputam o material reciclável com outros sujeitos, o que gera conflito.

A atividade relacionada à reciclagem do lixo tem permitido o abrigo de um exército de trabalhadores excluídos do mercado de trabalho. Segundo os dados levantados pela Secretaria Municipal de Meio Ambiente de Curitiba (SMMA), no ano de 2000, o número de carrinheiros na cidade de Curitiba era de aproximadamente 3.000, sendo que numa projeção da Prefeitura para o ano de 2007, o número teria dobrado, alcançando cerca de 6.000 carrinheiros. A estimativa para a RMC é de que esse número alcance, no mesmo período, a quantidade de 10.000 pessoas vivendo dessa atividade de coleta do lixo. A atividade com material reciclável apresenta certa diversidade no seu interior. Aqueles que não realizam diretamente a atividade da coleta do lixo estão envolvidos em outras atividades relacionadas, seja na qualidade de "dono de depósito de lixo", "locatário de carrinhos", que é o intermediário entre o "catador" e o "dono do depósito", seja, ainda, o de "comerciante de cavalos".

Essa diversidade está intimamente ligada às várias relações sociais que se estabelecem no interior dessa atividade, bem como nas próprias condições de coleta, que incluem os instrumentos utilizados, tais como: o carrinho e a carroça. A definição que distingue os trabalhadores parte do próprio instrumento de trabalho. Enquanto o carrinheiro é aquele catador de papel que anda a pé, puxando o carrinho, o carroceiro é o catador 
que se utiliza da carroça movida por tração animal. De forma indistinta a Prefeitura Municipal de Curitiba por meio do Departamento de Limpeza Pública utiliza a denominação de "coletores informais" para designar essa atividade, que se coloca em oposição ao serviço público de coleta realizado pela Prefeitura (Agência de Notícias da Prefeitura, 25 de abril de 2007). A própria designação adotada pelo Departamento de Limpeza Pública para denominar os catadores tem um sentido um tanto vaga, na medida em que adjetiva a atividade como sendo informal. Ademais, essa noção de informal é utilizada para explicitar toda atividade que se encontra "fora" de regulamentação legal, portanto, todos que a realizam encontram-se destituídos de direitos trabalhistas. Tal tratamento encontra-se em consonância com a política de limpeza urbana, onde os catadores e carroceiros são vistos como "problemas", pois segundo o Departamento de Limpeza, ao fazer a separação do lixo no local da coleta, seriam os responsáveis por espalhar o lixo pelas ruas, calçadas e galerias de águas pluviais, causando problemas.

A presença das crianças menores durante as atividades de coleta do lixo tem provocado uma série de conflitos envolvendo o Conselho Tutelar, que com intuito de "proteger" essas crianças, vem advertindo ou mesmo ameaçando de punição as famílias que as levam consigo por ocasião da realização do trabalho. As famílias têm alegado, por sua parte, que essa atividade é um trabalho como outro qualquer, não sendo restritivo às crianças pequenas, que ficam acomodadas nos carrinhos. Ademais, reclamam da ausência do Poder Público local em instalar creches no Jardim Icaraí a fim de que possam deixar seus filhos com segurança enquanto realizam a atividade nas ruas, que pode se estender ao longo do dia, muitas vezes, adentrando no período noturno.

No caso específico do Jardim Icaraí, as famílias não têm qualquer tipo de assistência do Poder Público, a não ser a de coação, no sentido da ameaça de serem retiradas da área e também pela presença da polícia quando realiza as rondas. É a idéia do Estado punitivo ou de que é necessário punir para que os resultados possam ser obtidos.
Na ausência de políticas públicas, a melhor política é a punição. Segundo relato dos moradores, quando a polícia faz a ronda no Icaraí, por meio da RONE (Ronda Ostensiva de Natureza Especial), a quantidade de carros muitas vezes é de cerca de 6 ou 7, intimidando e não oferecendo segurança, ao contrário, imprimindo mais temor do que proteção.

As trajetórias percorridas pelos carrinheiros são bastante longas, pois embora alguns já tenham um ponto fixo, seja uma loja, um shopping, um condomínio, a maioria recolhe de porta em porta das residências. Os carrinheiros saem no período da manhã percorrendo vários bairros da cidade de Curitiba, chegando a caminhar 10 ou mais quilômetros por dia e só retornam quando "enchem o carrinho": "Oia, vai fazendo, no Jardim, Boqueirão, no Centro. É a maioria vem pra esse lado aqui, ali ... pra esses lado aqui" (trecho retirado da entrevista com dona Neuza, realizada em setembro de 2006). A depender da distância percorrida e da quantidade de material disponível nas ruas, podem realizar duas ou mais viagens por dia para coletar o material e, assim, aumentar os rendimentos que dependem da qualidade e a quantidade .

\section{A Coleta}

O termo coleta aqui utilizado designa as condições implícitas e explicitas de todo o processo que envolve o uso e a apropriação do material encontrado. Envolve uma série de "práticas sociais" que se relacionam desde a organização da saída ao processo de coleta propriamente dito até as redes de relações estabelecidas na rua, que podem se dar de forma conflitiva ou não. Trata-se, a coleta, de um conceito operacional aqui considerado para descrever as estratégias de obtenção do "material reciclável" por um determinado grupo social. Ele serve, ainda, para explicar a "realidade empiricamente observada", caracterizando os conflitos e contradições vividas cotidianamente pelos carrinheiros e carroceiros e, nesse sentido, ele é construído. A respeito da construção de conceitos operacionais que possam explicar uma infinidade de situações, pode-se fazer referência à noção de "processo de ambientalização" que 
para Lopes (2004), é a incorporação de uma prática que envolve discurso e hábito de natureza ambiental. Ou "processo de devastação", que é utilizado por Almeida para descrever a destruição das palmeiras de babaçu na região Norte e Nordeste do Brasil (ALMEIDA et alii, 2005, pp. 2731).

Alguns carrinheiros e carroceiros já possuem uma espécie de trajetória fixa, pois já estabeleceram uma relação com os locais de coleta. Fazem a coleta em locais previamente acertados. Nessa situação, agendam com os donos dos estabelecimentos ou responsáveis, dia e hora para a retirada do material, sendo que o descumprimento dessa agenda incorre no risco de ficar sem a carga daquele dia. Essa relação tem se mostrado bastante frágil, pois quem produz o lixo quer se livrar o mais rápido possível de tudo aquilo que considera entulho. Então, caso o carrinheiro ou carroceiro deixe de passar no horário, o lixo é entregue ao primeiro que passar, independentemente de quem seja, isto é, não há qualquer tipo de fidelidade ou de laços que possam assegurar essa "relação de trabalho". Dessa forma, são obrigados a se alternarem nos bairros de acordo com os dias do serviço de coleta do caminhão do lixo. Numa tentativa de antecipar o caminhão, os carrinheiros e carroceiros percorrem os mesmos trechos, coletando o material reciclável que é colocado pelos moradores, já que a maioria retira os resíduos sólidos para fora de suas residências seguindo a indicação do calendário de coleta, distribuído ao longo do dia.

A prática de coleta de material reciclável realizada desde há muito, fez com que os carrinheiros e carroceiros acompanhassem de perto os programas e a rotina de limpeza do serviço público da cidade, sobretudo porque esse sistema tem se colocado em algumas situações de forma concorrente, restringindo a atividade a alguns poucos locais, na medida em que recolhem os lixos de forma antecipada. Os carrinheiros encontram-se numa batalha com os caminhões numa tentativa de antecipar a sua atividade. A grande maioria das famílias - quase $90 \%$ delas, conforme apontado pelos moradores entrevistados -, são catadores de papel, de material reciclável. Indistintamente, essa atividade envolve um leque de pessoas que, embora tendo outras qualificações e experiências profissionais diversas, são lançadas a essa atividade em função das dificuldades de se inserirem no mercado formal de trabalho.

O fato de o Departamento de Limpeza Pública estabelecer distintos horários para a coleta dos resíduos sólidos urbanos poderesultar numa estratégia no sentido de evitar que os carrinheiros ou carroceiros antecipem a coleta oficial. Evidencia-se, nesse processo, uma disputa pelos resíduos sólidos urbanos, em que a "parte mais forte" - o Departamento de Limpeza da Pública da Prefeitura Municipal - estabelece e impõe regras desconsiderando esse conjunto de agentes sociais que também realizam a limpeza da cidade. Os carrinheiros e carroceiros igualmente disputam o lixo com outros agentes (empresas, lojas, condomínios, instituições de caridade, clubes...), que "descobriram" o valor econômico dos resíduos sólidos, que se presta para ser reciclado. O material que era tido como lixo para esses agentes e que era coletado pelos carrinheiros e carroceiros passou a ser vendido por esses próprios agentes, importando salientar que alguns deles são grandes produtores de resíduos e por isso mesmo têm melhores condições, vendendo o lixo diretamente para as empresas de reciclagem, eliminando a figura do atravessador. Essa mudança de postura de tais agentes sociais diante dos resíduos sólidos urbanos está relacionada á incorporação de um discurso e de uma prática ambiental, aquilo que Lopes (2004) tem denominado de "processo de ambientalização", como referido anteriormente. O conjunto de agentes envolvidos na atividade de coleta e reciclagem de resíduos sólidos vem provocando a diminuição qualitativa e quantitativa do material que o carrinheiro e carroceiro têm acesso, sendo que esse processo vem aprofundando a exclusão. Observa-se que se tem delineado a exclusão no interior da própria exclusão, impulsionada pelos interesses em torno da atividade de reciclagem, que vem ganhando cada vez mais importância econômica em função do crescimento da indústria de reciclagem. Os materiais que alcançam um preço melhor no mercado de reciclados são mais difíceis de serem encontrados por serem mais disputados não só 
pelos carrinheiros e carroceiros, mas por outros sistemas de coleta.

Os riscos durante a coleta do material são muitos e enormes, pois além de estarem ligados diretamente com a manipulação do lixo, ficam expostos na rua, dividindo o espaço com todo tipo de veículo que transita pelas ruas e avenidas da cidade. Os carrinheiros e carroceiros circulam pelas mesmas vias que os automóveis, em pistas rápidas ou não, seguindo as suas próprias orientações, demonstrando o total desconhecimento das leis do trânsito. Ademais, tentam "economizar os caminhos", cortando as ruas e avenidas em todos os sentidos, sem dar importância à sinalização do tráfego. Por conta disso, os acidentes envolvendo os carrinheiros e carroceiros são freqüentes nas ruas da cidade; a despeito de não haver dados estatísticos oficiais que possam ser apresentados, este fato é confirmado pelos carrinheiros do Jardim Icaraí. Os acidentes no trânsito que dizem respeito às colisões entre as carroças e carrinhos e os veículos provocam diferentes danos, que vão do atropelamento do condutor do carrinho até uma simples colisão.

Aumentar a capacidade de carga do carrinho é uma estratégia muito utilizada pelos catadores, pois significa potencializar em muito os rendimentos com a venda do material reciclado. Essa estratégia é importante quando não conseguem realizar mais de uma viagem no mesmo dia, em função das longas distâncias percorridas e do desgaste físico que envolve esse tipo de trabalho. Então, quanto mais quantidade e qualidade puderem ser agregadas numa mesma carga, maiores rendimentos poderá obter. O grande esforço físico, no entanto, não se traduz necessariamente numa duplicação dos rendimentos a serem obtidos. As conseqüências do esforço físico para suportar tamanha quantidade de peso podem ser percebidas nas diversas entrevistas: O trabalho necessário para conduzir esse peso em longas viagens, significa muito pouco diante do tamanho do desgaste físico que isso representa.

Os carrinheiros são os trabalhadores que se encontram mais desprovidos de condições financeiras, por isso mesmo, encontram-se em situação de maior precariedade com relação ao desenvolvimento da atividade da coleta do material. A maioria dos carrinheiros não possui seu próprio carrinho para as atividades. Desta forma, veêm-se obrigados a alugar o carrinho dos donos de depósitos de material reciclável ou mesmo de outros carrinheiros que se encontram em melhores condições econômicas. Aquele que necessita alugar o carrinho está numa situação econômica mais desvantajosa, pois além de trabalhar para fazer o seu sustento e de sua família, ainda tem o compromisso de efetuar o pagamento do aluguel. Então, acaba obrigado a retornar para as ruas quantas vezes for preciso enquanto está de posse do carrinho para conseguir o material necessário a fim de pagar as suas despesas.

As necessidades sempre prementes tornam esses carrinheiros bastante vulneráveis, o que tem resultado numa total incapacidade de projetar o seu próprio futuro. Os sonhos sempre ficam "adiados" em função da urgência do presente, que tem se demonstrado bastante desafiador. A necessidade de vender 0 produto de imediato, ou ao fim do dia, obriga os carrinheiros a realizarem uma dupla jornada de trabalho, que envolve além da coleta, a separação do material para ser vendido assim que chegam da rua. Por isso mesmo, os próprios carrinheiros valorizam aqueles que conseguem no processo da coleta ir organizando no próprio espaço do carrinho o lixo coletado, pois esse procedimento facilita em muito o trabalho posterior. Além disso, a maioria desses carrinheiros não possui locais para exercer essa atividade, que é feita em suas próprias residências ou na rua, em frente às suas casas. O final da tarde no Jardim Icaraí lembra uma grande feira, onde os carrinhos chegam abarrotados de material, que são colocados na rua para serem separados.

Por sua vez, os chamados "atravessadores" ou donos de depósitos revendem o material para as empresas de reciclagem. Isto é, o lucro dos carrinheiros fica nas mãos desse agente, que intermedeia o negócio com as indústrias de reciclagem de lixo. O fato dos "atravessadores" possuírem melhores condições econômicas Ihes permite, também, negociar o 
material, inclusive, aguardar o melhor momento para a venda dos materiais que se encontram em melhor cotação no mercado do lixo. Essa relação do carrinheiro com o "atravessador" ou dono do depósito é baseada na dependência e na exploração. Aqueles que não possuem o carrinho e sequer possuem lugar para morar podem "ficar" no próprio barracão onde é realizada a separação e o depósito do lixo. Assim, se obrigam a utilizar o carrinho do "atravessador" ou do dono do depósito. Nesse sentido, ficam sujeitos às regras contratuais previamente determinadas, que se estabelecem segundo uma tradição oral e que atendem os interesses dos "atravessadores" ou donos de depósitos.

Associada aos carrinheiros e carroceiros, há a "indústria" de carroças e os comerciantes de cavalos. Eles têm sua importância nessa rede, pois contribuem fornecendo os instrumentos de trabalho que são utilizados no processo de coleta. Chama atenção o número de comerciantes de cavalos no próprio Jardim Icaraí, que segundo os moradores, vêm aumentando nos últimos anos. É possível observar inclusive, o aumento do número de cavalos na cidade de Curitiba, que pode ser constatado pelo aumento do número de carroceiros que circulam pelas ruas, bem como pela quantidade de animais que pode ser vista em algumas áreas verdes.

A convivência de formas modernas e tradicionais, como observado em Curitiba, no aumento da quantidade de cavalos circulando pelas ruas juntamente como carros de última geração, revela o que Santos chama de adaptações dos imperativos da modernização globalizadora, que a cidade "reúne e associa pedaços de tempo materializados de forma diversa, autorizando comportamentos econômicos diversos" (SANTOS, 1999. p. 243) Nesta perspectiva é que se pode compreender a razão da convivência de formas tão distantes e diferentes do ponto de vista da evolução das tecnologias e do trabalho, no espaço urbano, onde objetos técnicos mais modernos encontram-se lado a lado com os cavalos, carroceiros e carrinheiros do Jardim Icaraí.

O trabalho e a vida dos carrinheiros e carroceiros de material reciclável é um intricado labirinto de estreitos e permanentes contatos com o lixo. Suas vidas são marcadas por longas jornadas, que não se encerram com a atividade de coleta, pois vivem o tempo todo em contato com o lixo, seja porque este é depositado na sua própria casa, seja porque a sua própria casa foi construída por meio desse lixo, seja porque toda sua reprodução depende quase que exclusivamente dessa atividade. Paradoxalmente para as famílias do Jardim Icaraí, o lixo é vida. Elas descobriram no lixo, uma forma de superação, em princípio, de suas carências materiais, sendo que isso permitiu a construção de outras sociabilidades necessárias para se situar no mundo urbano tão adverso, que lhes retira o direito de usufruir da própria cidade. Elas vivem a cidade pelo avesso, ou seja, pela margem do consumo da cidade devido à sua própria condição social. Em outras palavras, o material impróprio na reprodução e expansão da cidade é apropriado pelas mãos dos carrinheiros e carroceiros, ganhando um novo significado.

É nesse processo que os carrinheiros e carroceiros se refazem e se transformam, e, submetidos às mais aviltantes condições de trabalho e vida, imprimem significado ao que fazem e encontram motivos para continuar na rua. No Jardim Icaraí, onde as condições de moradia e de trabalho são constantemente colocadas à prova, representa para os moradores uma grande capacidade de reinvenção das condições materiais e simbólicas para que possam lidar com as forças adversas que se encontram tanto no plano interno como no externo, quando estão realizando a coleta do lixo. Aqui adaptando as palavras de Santos "Trata-se para eles da busca de um futuro sonhado como carência a satisfazer - carência de todo tipo de consumo, consumo material e imaterial" (SANTOS, 1999, p. 280). Importa enfatizar mais uma vez que a coleta é um desafio, que submete os carrinheiros e carroceiros a toda sorte, pois realizam uma atividade que não Ihes dá nenhuma garantia de que vão obter os resultados que necessitam, ou mesmo de retornar para suas casas ao final da extensa jornada de trabalho.

$$
\text { Conforme depoimentos dos }
$$
carrinheiros, na realização da coleta do material 
reciclável, sofrem todo tipo de preconceitos e discriminações, pois a população de um modo geral os olha com desconfiança e medo, receando qualquer tipo de contato, como se fossem doentes, passíveis de contaminar as demais pessoas. A situação acima mencionada se configura como explicitação da violência, pois conforme Pedrazzini "ser indiferente ao próximo miserável é uma violência simbólica praticada por milhões de seres humanos" (PEDRAZZINI, 2005, p.73). Manter distância dos carrinheiros e carroceiros é a regra; além disso, uma forma de hostilidade e de ignorálos. A sua invisibilidade é quebrada em alguns momentos, sobretudo quando aparecem como problema, atrapalhando o fluxo de veículos que transitam pelas ruas e avenidas quase sem se importar com esses sujeitos, que mais se assemelham a mendigos. Visto por esse ângulo, perdem a condição de sujeitos e se transformam em coisas que impedem o fluxo normal dos veículos. Nesse sentido, diferentemente de outras interpretações, incomoda à população a publicização dessa pobreza. A situação mencionada anteriormente representa uma face da violência vivida na realização da coleta, que se expressa cotidianamente na rua, embora no lugar de moradia também se manifeste sobre outros contornos, que podem ser percebidos segundo as diferentes formas de olhar.

\section{A Violência}

As ocupações urbanas constituem-se num processo de expansão da cidade e esse processo tem sido compreendido como resultado da violência da urbanização, isto é, a própria urbanização é violenta, pois fragmenta o território, produzindo a segregação e a exclusão Pedrazzini (2006: p. 93). Para esse autor, a "favela" seria o maior exemplo e a eterna vítima territorial da urbanização, pois a sua interpretação tem se dado a partir de sua própria existência social, às vezes, mal interpretadas, pois construídas para dar conta desse processo de marginalização (WACQUANT, 2001, p.93-107). Os estudos sobre a "favela" abstraem-se do dado empírico e de uma compreensão baseada nas reais condições de existência desses fragmentos urbanos, por isso, se constrói outra realidade social, resultando numa interpretação equivocada ou distorcida. É importante frisar que a situação aqui descrita não é particularidade do Jardim Icaraí, mas pode ser encontrada nas grandes cidades brasileiras, onde houve uma transformação do crime, que sofreu um processo de "modernização", implementando "novas estratégias" de ação e atuação, situadas para além das previsões legais e, por isso mesmo, às vezes, passíveis de serem punidas; estudos mais recentes têm focalizado a problemática "da modernização da violência", procurando compreender essa nova face do crime.

O Jardim Icaraí, com exceção da água fornecida pela SANEPAR, não conta com nenhum tipo de serviço público. As políticas sociais chegam aos bairros próximos, inclusive a ocupações vizinhas (como por exemplo, a do Jardim Alvorada e a do Jardim União), mas não se estendem ao Jardim Icaraí, fazendo com que seus moradores se dirijam a esses locais para obter alguns serviços. Acredita-se que os serviços não são oferecidos no local em função de um processo de "regularização fundiária", que vai resultar no que se denomina de "remoção" ou no "reassentamento" de parte dos moradores do Jardim Icaraí para outro local. O vazio deixado pelo Estado vem permitindo a disseminação de outras práticas circunscritas a outras formas de poder e de controle sobre o Jardim Icaraí. Neste sentido, vive-se ali uma sociabilidade violenta, que emerge e se origina em resposta aos problemas demandados e não sanados e que se explicita no cotidiano dos moradores.

As normas e as regras de convivência, conforme visto, advêm dos arranjos estabelecidos entre todos os moradores que se encontram situados nos estreitos limites das possibilidades de diálogo. Contudo, o diálogo não se efetiva quando somente um lado dita o que pode e o que não pode ser feito, em se tratando de comportamentos relativos à segurança, sobretudo se esse comportamento pode colocar em questão a mobilidade e a garantia das atividades desse mesmo grupo que dita às regras. É interessante observar que o cotidiano das famílias do Jardim Icaraí é regido por situações de superação constante, incluindo a superação 
do medo, já que se convive com ele diariamente. O Jardim Icaraí como um todo é constantemente monitorado. Nesse sentido, é possível afirmar que a cautela é uma regra de convivência, embora não explicitada enquanto tal. Trata-se de um princípio orientador de todas as práticas cotidianas e que se encontra incorporada nas vidas dessas famílias.

O Fato de o Jardim Icaraí estar localizado do "outro lado da linha do trem " reforça os estigmas sociais. O "outro lado da linha" onde a violência aparece como um forte elemento que constitui o lugar pode ser compreendido como resultante da desestruturação urbana em que a violência do grupo ou grupos de jovens ali residentes manifesta-se como "uma 'forma de relação extrema' com um mundo em permanente estado de urgência de com Pedrazzini(grifo do autor). Imersos na violência 'total' de uma favela 'globalizada', pela violência da urbanização, os indivíduos são estimulados a reagir de modo violento" (PEDRAZZINI, 2006, p. 75)

Nesse sentido, esse(s) grupo(s) cobre $(\mathrm{m})$ uma espécie de "lacuna" deixada pelo Estado. Eles acabam por fazer a segurança, pois o "problema deles" é com os seus adversários e não com os moradores. A falta de oportunidade e de emprego conforme depoimento dos moradores é um dos principais motivos da violência. "É $O$ culpado de tá dando tanto banditismo é esse desemprego... farta de trabaio, farta de ocupação (trecho retirado da entrevista do Sr. Ambrósio, realizada em julho de 2006). A sua leitura permite perceber a inter-relação do que ocorre no Jardim Icaraí com contextos mais globais, ultrapassando uma visão reducionista que tenta explicar a violência como problema localizado e moral e, nesse sentido, se aproxima das discussões teóricas sobre o tema.

A origem desse tipo de violência é resultado de um processo, que se encontra relacionado à modernização da economia (WACQUANT, 2001), aliado à omissão do Estado em políticas efetivas que possam dar condições às pessoas de poderem decidir sobre as suas próprias vidas. Diante da omissão do Estado e da exacerbação da violência alcançando outros espaços da cidade, a presença do Estado se faz sob a forma de criminalizar a miséria (WACQUANT, 2003), numa tentativa de retirar do convívio social todo aquele que representa algum tipo de ameaça à ordem estabelecida. Essa "nova política" que se define pelo confinamento das pessoas tidas como "perigosas", dá-se pelo encarceramento e por uma forma mais sutil, mas tão perversa quanto à primeira, que é a produção de espaços urbanos residuais, que procuram manter as pessoas isoladas. Nesses lugares "periféricos", de total abandono, a presença do Estado tem se dado prioritariamente através dos aparatos policiais repressivos, o que faz com que os moradores sintam medo e insegurança diante da presença da polícia, que trata de forma indiscriminada qualquer morador pelo fato de ser do Jardim Icaraí, o que em si mesmo, já é um fator de incriminação.

A reflexão acerca da violência aqui desenvolvida fornece alguns elementos para a compreensão de que os moradores residentes nesses territórios tidos como "marginais" não são mais violentos do que os moradores de outros bairros da cidade. O que ocorre é que por uma série de carências não atendidas encontram-se mais expostos a todo tipo de violência. Assim, buscam contrabalançar esse nível de exposição utilizando-se de diversos mecanismos, inclusive ilegais e violentos que reforçam a imagem negativa que já se tem deles (PEDRAZZINI, 2006, p.101), sendo que por isso mesmo, o olhar de "fora" tem que ser cuidadoso e precavido, pois os problemas que aparecem de forma localizada têm suas articulações que são mais amplas e profundas, inclusive relacionadas ao processo de urbanização. A urbanização, segundo Pedrazzini (2006), produz a violência na medida em que fragmenta o espaço, criando territórios de inclusão e exclusão. Nesse sentido, o fato da urbanização ser um processo intimamente relacionado a determinados interesses econômicos, faz com que os instrumentos urbanísticos estejam a serviço da efetivação desses interesses. As políticas de intervenção para o Jardim Icaraí encontram-se em dissonância com o que pensam as famílias acerca do lugar, pois resultam em formas e conteúdos diferentes.

\section{Considerações Finais}


A construção do Jardim Icaraí, a forma de assentamento humano que se deu via a ocupação da área, considerada pelo poder público como "irregular"; o trabalho representado pela coleta de material reciclável, por ser a principal atividade desenvolvida pela maioria das famílias; a violência, por se constituir num elemento que permeia o cotidiano das famílias do Jardim Icaraí e o conflito sócioambiental, já que se trata de uma ocupação sobre uma área de proteção ambiental, a APA do Iguaçu, são elementos importantes na constituição do Jardim Icaraí enquanto um fragmento urbano, produzido como resíduo das políticas urbanas atuais.

Embora as ocupações urbanas tenham se tornado parte da história da expansão das cidades brasileiras, o fenômeno das ocupações em si toma a forma da ilegalidade uma vez que para se viver na cidade é preciso usufruir do poder de compra da terra urbana. Assim, a cidade é produzida e reproduzida tendo como base a propriedade privada do solo urbano, por isso as ocupações colocam-se frontalmente contra essa lógica. Esta é a razão pela qual são consideradas "irregulares", mesmo considerando a "função social da propriedade", que se encontra disposta na Constituição Federal de 1988 e no Estatuto da Cidade. Os assentamentos humanos resultantes do processo de "ocupação" sejam denominados de "bairros", "vilas", "favelas" ou "jardins", independentemente do nome, configuram-se por conter na sua formação processos distintos conferindo-Ihes certas particularidades.

No processo de construção do Jardim Icaraí pôde ser observado algumas dessas particularidades. Dentre estas, destaca-se o próprio processo de "ocupação" da área, contrariando e pondo em questão a forte presença do poder público planejador e disciplinador do uso do solo da cidade de Curitiba. Outro aspecto importante que deve ser considerado, é que esta ocupação deu-se sobre uma Área de Proteção Ambiental, que se encontrava degradada

Além disso, organizaram uma infraestrutura mínima, como a abertura e aterramento das ruas, uma rede de água e energia de forma artesanal, mas que Ihes permitiu as condições para permanecer na área. Todas estas estratégias utilizadas na consecução das condições materiais necessárias para se estabelecerem no local representam diferentes momentos e formas de produção do espaço do Jardim Icaraí, e por que não dizer, da cidade de Curitiba, já que não é possível dissociar as "ocupações urbanas" das dinâmicas mais amplas de produção do espaço da cidade. Nesse sentido, o Jardim Icaraí também representa uma forma da produção de Curitiba, ainda que seja um paradoxo em face de todos os esforços do Poder Público Municipal em torná-la hermética a esse tipo de problema.

A cidade não é um ente separado da sociedade que a produz. Ela, a cidade, é resultado também dos diferentes agentes e projetos em curso. É na sua espacialidade que se manifestam as suas contradições e conflitos, sendo que os conflitos sócio-ambientais representam, antes de tudo, conflitos pelo uso, pelo direito à cidade, mas que muitas vezes tomam a aparência de ambientais em razão da incorporação do discurso ambiental. Para além dessa dimensão, o que está em jogo são os usos da cidade, definidos nos planos de zoneamento urbano, que a esquadrinham e determinam os lugares de cada coisa, das pessoas.

No momento atual, como apontam vários estudos sobre a cidade, já não é somente a terra urbana que tem preço, mas a própria cidade é transformada em mercadoria e seu acesso se torna cada vez mais distante de uma imensa massa de moradores, dados os altos custos dessa mercadoria. A cidade é palco dos mais diferentes projetos; há que se apontarem, entretanto, como importante indutor desses processos, as políticas urbanas, aliadas muitas vezes às políticas privadas que, agindo sobre o território das cidades, contribuem de forma anunciada, ou velada para o recrudescimento de conflitos de toda ordem. Nas últimas décadas, o conflito mais relevante e palpável, presente nas grandes cidades brasileira, mais visível até mesmo que o de natureza ambiental, tem sido a violência, sob diferentes formas. Seja no trânsito, na ostensividade do consumo, na insegurança, principalmente nos assaltos à mão armada e crimes das mais diversas naturezas. 
Para além desse debate, o que importa aqui, é afirmar que na esteira desses conflitos urbanos, a variável ambiental pode, "mascarar" outras tensões, que se colocam muitas vezes mais contundentes e que são diluídas pela dimensão ambiental. No Jardim Icaraí, a força do conflito que ganha os contornos de sócioambiental é em primeiro lugar pelo direito á cidade, expresso pelo direito à moradia. Contudo, é importante ressaltar que, em se tratando de um estudo que toma a cidade de Curitiba como locus de investigação, as conclusões nos remetem ao grande investimento que vem sendo realizado para posicionar Curitiba no circuito de desenvolvimento econômico passível de dar a esta cidade as condições de disputar um lugar relevante no contexto da urbanização contemporânea.

Vale ressaltar que o Jardim Icaraí, sendo uma ocupação considerada "irregular", já anuncia um embate pela terra urbana. A necessidade de abrigo, de moradia, é condição primeira de garantia da reprodução física e social do ser humano; portanto, as ocupações urbanas, em função da garantia de moradia revelam um dado fundamental do conflito que tem sua origem na negação de um direito à cidade (LEFEBVRE, 2001). O fato do Jardim Icaraí se encontrar numa área de proteção ambiental, torna a situação das famílias que lá se encontram muito mais dramática e aguça as tensões, pois a variável ambiental contém um forte apelo social e toda uma legislação que serve de amparo às ações do Poder Público local. Ali é flagrante o confronto, que envolve distintos projetos para a cidade e distintas orientações para a preservação do meio ambiente. A atividade que desenvolvem e a forma como os moradores construíram as condições para viver permite compreender, sobretudo, que a cidade se produz sob tensões, a revelarem muitas vezes outras formas de produção do urbano para além dos esquemas da tecnocracia, do planejamento. A cidade se compõe de um emaranhado de

categoria de análise da produção de Curitiba/ Jardim Icaraí".

\section{Nota:}

projetos cujo conteúdo material e simbólico estão em permanente confronto.
${ }^{1}$ Este artigo se constitui de parte da reflexão da pesquisa para a tese de doutorado intitulada: "Conflitos sócioambientais urbanos: o lugar como

\section{Bibliografia}

. (2001). Sentidos da sustentabilidade urbana. In: ACSELRAD, Henri. A duração das cidades: sustentabilidade e risco nas políticas urbanas. Rio de Janeiro: DP\&A, p.27-55.

. (2004a). As práticas espaciais e o campo dos conflitos ambientais. In: ACSELRAD, Henri. Conflitos ambientais no Brasil. Rio de Janeiro: Relume Dumará, p.13-35.

(2004b). Justiça ambiental: ação coletiva e estratégias argumentativas. In: ACSELRAD, Henri et al. (Org.). Justiça ambiental e cidadania. 2.ed. Rio de Janeiro: Relume Dumará, p.23-39.
ALMEIDA, Alfredo Wagner Berno de; SHIRAISHI NETO, Joaquim; MARTINS, Cynthia Carvalho. (2005). Guerra ecológica nos babaçuais: o processo de devastação dos palmeirais, a elevação do preço de commodities e o aquecimento do mercado de terras na Amazônia. São Luís: Lithogra.

LEFEBVRE, Henri. (1991). O direito à cidade. São Paulo: Ed. Moraes, 1991c. 
LIMA, Rosirene Martins. (2008). Conflitos sócioambientais urbanos: o lugar como categoria de análise da produção de Curitiba/ Jardim Icaraí. Tese de Doutorado, Curitiba, Doutorado em Meio Ambiente e Desenvolvimento Universidade Federal do Paraná.

LOJKINE, Jean. (1997). O estado capitalista e a questão urbana. Trad. Estela dos Santos Abreu. São Paulo: Martins Fontes.

LOPES, José Sérgio Leite. (2004). A "ambientalização" dos conflitos sociais. In: LOPES, José Sério Leite (Coord.). A ambientalização dos conflitos sociais. Rio de Janeiro: Relume Dumará, p.17-38.

. (2006). Sobre processos de "ambientalização" dos conflitos e sobre os dilemas da participação. Revista Horizontes Antropológicos, ano 12, n.25, p.31-64, jan./jun.

MARTINS, José de Souza. (2002) A sociedade vista do abismo: novos estudos sobre exclusão, pobreza e classes sociais. Petrópolis (RJ): Vozes.

MOURA, Rosa. (2001). Os riscos da cidade modelo. In: ACSELRAD, Henri (org.). A duração das cidades: sustentabilidade e riscos nas políticas urbanas. Rio de Janeiro: DP\&A, p.203-237.

. (2004) Políticas públicas urbanas: ausências e impactos. In: MENDOÇA, Francisco (Org.). Impactos socioambientais urbanos. Curitiba: UFPR. p.149-168.

PEDRAZZINI, Ives. (2006). A violência das cidades. Petrópolis (RJ): Vozes.
SÁNCHEZ, Fernanda. (2001). A (in)sustentabilidade das cidades-vitrine. In: ACSELRAD, Henri. (Org.). A duração das cidades: sustentabilidade e riscos nas políticas urbanas. Rio de Janeiro: DP\&A, p.155-175.

SANTOS, Boaventura de Sousa. (1988). O discurso e o poder: ensaio sobre a sociologia

da retórica jurídica. Porto Alegre: Fabris.

SANTOS, Milton. (1999). A natureza do espaço: técnica e tempo, razão e emoção. 3.ed. São Paulo: Hucitec.

. (2000). Por uma outra globalização: do pensamento único a consciência universal. 4.ed. Rio de Janeiro: Record.

. (2004). O espaço dividido: os dois circuitos da economia urbana dos países subdesenvolvidos. 2.ed. São Paulo: USP.

VAINER, Carlos. (2000). Pátria, empresa e mercadoria: notas sobre a estratégia discursiva do planejamento In: ARANTES, Otília Beatriz Fiori; MARICATO, Ermínia. A cidade do pensamento único: desmanchando consensos. 2.ed. São Paulo: Vozes. p.75-104.

WACQUANT, Loic. (2001). Os condenados da cidade. Trad. João Roberto Martins Filho. Rio de Janeiro: Revan; FASE.

(2003). Punir os pobres: a nova gestão da miséria nos Estados Unidos. Trad. Eliana Aguiar. Rio de Janeiro: Revan. 